\title{
Determinasi Revisit Intention Ditinjau Dari Destination Image Melalui Customer Satisfaction di Kampung Inggris Pare - Kediri
}

\author{
(Determinant Of Revisit Intention Reviewed From The Destination Image \\ Through Customer Satisfaction In English Village Pare - Kediri)
}

\author{
Muhammad Dian Ruhamak, Yudiarto Perdana Putra ${ }^{2}$ \\ 1,2Fakultas Ekonomi Universitas Kadiri, dianru@unik-kediri.ac.id \\ 1'dianru@unik-kediri.ac.id, ${ }^{2}$ yudiarto@unik-kediri.ac.id
}

\begin{tabular}{l}
\hline Info Artikel \\
\hline Diterima Agustus 1, 2020 \\
Direvisi Agustus 20, 2020 \\
Dipubikasi September 20, \\
2020
\end{tabular}

\section{Kata Kunci:}

Revisit Intention, Destination Image, Customer Satisfaction

\section{Keywords :}

Revisit Intention, Destination Image, Customer Satisfaction

\begin{abstract}
Abstrak
Berdasarkan uraian latar belakang maka tujuan dari penelitian ini adalah menganalisis Pengaruh Destination Image terhadap Revisit Intention Melalui Customer Satisfaction di Kampung Inggris di Kabupaten Kediri. Dimana populasi dalam penelitian ini adalah siswa yang kursus di kampung inggris sejumlah 87 responden. Metode pengumpulan data menggunakan kuesioner dan wawancara. Dalam melakukan analisis data digunakan partial least square yang meliputi uji outer model untuk validitas dan reliabilitas, pengujian inner model dan hipotesis. Dari hasil pengujian citra destinasi berpengaruh signifikan terhadap kepuasan konsumen yang mana kepuasan tersebut semakin mendorong konsumen untuk datang berkunjung kembali serta kepuasan konsumen memediasi citra destinasi terhadap minat berkunung kembali secara sempurna.
\end{abstract}




\section{PENDAHULUAN}

Bahasa inggris merupakan kebutuhan penting dalam menghadapi persaingan baik di dunia usaha maupun dunia pendidikan. Sehingga sejak memulai pendidikan di sekolah dasar sudah mulai diperkenalkan dengan bahasa inggris. Namun terkadang porsi pembelajaran di sekolah masih dirasakan kurang sehingga dirasa perlu adanya alternative untuk menambah kemampuan berbahasa inggris agar lebih baik yakni mencari lembaga kursus, dimana salah satu destinasi favorit yang menjadi pilihan adalah Kampung Inggris yang terletak di kota pare yang mana kawasan tersebut berada di bagian timur laut kabupaten Kediri yang berbatasan langsung dengan kabupaten Jombang.

Lembaga kursus di Kampung Inggris pertama kali didirikan oleh Mr. Kalend Osen (al-jum'ah, 2018) memperoleh predikat sebagai wisata edukasi karena lebih dari seratus lembaga kursus yang berdiri di lokasi tersebut. Berbagai cara dilakukan dalam memperoleh informasi mulai dari melihat jejaring sosial, teks, gambar dan video di website yang digunakan oleh setiap lembaga dalam memasarkan produk mereka. Beberapa konsumen ada yang berkunjung langsung ke kampung inggris agar mengetahui bagaimana metode pembelajaran yang diterapkan lembaga kursus sehingga konsumen dapat menentukan pilihan yang tepat.

Revisit intention langsung ke kampung inggris dipengaruhi oleh beberapa faktor yang menjadi pertimbangan, diantaranya Destination Image yaitu kombinasi variasi produk, atraksi, dan atribut yang ditambahkan ke kesan dari proses seleksi berdasarkan berbagai informasi (Whang et al., 2016), Selain itu Destination Image merupakan persepsi seseorang tentang produk, objek, perilaku dan peristiwa yang didorong oleh kepercayaan, perasaan dan serangkaian tujuan yang memiliki ide dan harapan untuk tempat atau perjalanan tertentu (Stylos et al., 2016). Pengalaman yang dibagikan oleh orang yang pernah belajar di kampung inggris melalui cerita, website maupun media social dimana informasi tersebut cepat tersebar dan diakses dengan begitu mudah yang secara tidak langsung membantu memasarkan lembaga agar lebih dikenal konsumen..

Ulasan yang baik didasari oleh perasaan puas yang dirasakan konsumen dimana 
semakin puas konsumen maka ulasan yang diberikan akan semakin baik (Samsudin \& Worang, 2016), begitu pula sebaliknya semakin tidak puas konsumen semakin buruk pula ulasan yang diberikan..

Kampung Inggris terletak di antara Desa Pelem dan Tulungrejo Kecamatan Pare Kabupaten Kediri Provinsi Jawa Timur. Kampung Inggris memperoleh predikat sebagai wisata edukasi karena lebih dari seratus lembaga kursus yang berdiri di lokasi tersebut. Selain itu ada juga wisata lain yang terletak di sekitar lokasi tersebut antara lain candi surowono dan tegowangi, pemandian surowono, monumen simpang lima gumul dan lain sebagainya yang dapat menarik minat konsumen berkunjung.

Konsumen harus pandai dalam memilih lembaga yang tepat,, selain itu program yang ditawarkan lembaga haruslah bervariatif yang dapat menciptakan kesan bagi konsumen sehingga akan berdampak terhadap Revisit Intention.

Rumusan masalah dalam penelitian ini adalah bagaimana Pengaruh Destination Image terhadap Revisit Intention Melalui Customer Satisfaction di Kampung Inggris di Kabupaten Kediri.

Tujuan penelitian ini adalah menganalisis Pengaruh Destination Image terhadap Revisit intention Melalui Customer Satisfaction di Kampung Inggris di Kabupaten Kediri.

Pemilihan kampung inggris dipilih sebagai objek penelitian karena perkembangan desa wisata saat ini sedang menjadi daya tarik pengunjung di berbagai tempat di seluruh Indonesia sehingga pemerintah daerah memaksimalkan potensi yang ada di wilayahnya dengan membentuk ikon pariwisata yang menjadi daya tarik terhadap wisatawan lokal maupun mancanegara.

Berdasarkan dari rumusan masalah dan tujuan penelitian maka dapat digambarkan kerangka konseptual seperti berikut ini : 


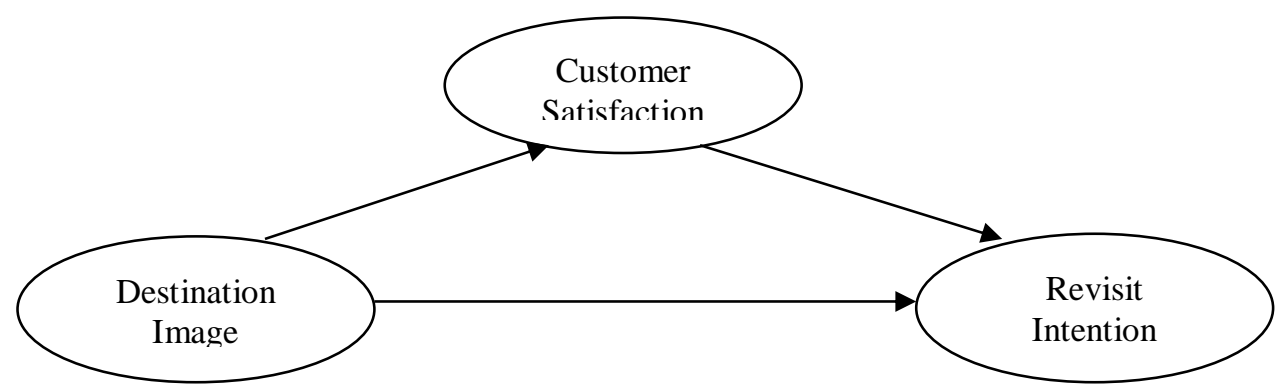

Dari gambar kerangka diatas dapat diperoleh 4 hipotesis antara lain :

H1 = Destination Image berpengaruh signifikan terhadap Customer Satisfaction

$\mathrm{H} 2$ = Destination Image berpengaruh signifikan terhadap Revisit Intention

H3 = Customer Satisfaction berpengaruh signifikan terhadap Revisit Intention

$\mathrm{H} 4$ = Destination Image berpengaruh signifikan terhadap Revisit Intention melalui Customer Satisfaction

\section{METODE PENELITIAN}

\section{Populasi}

Populasi adalah wilayah generalisasi yang terdiri atas: obyek/subyek yang mempunyai kualitas dan karakteristik tertentu yang ditetapkan oleh peneliti untuk dipelajari dan kemudian ditarik kesimpulannya (Sugiyono, 2016).

Populasi dalam penelitian ini adalah siswa yang kursus di lembaga kursus bahasa inggris di kampung inggris baik secara online maupun offline pada bulan juni - agustus 2020 sebanyak 87 responden

\section{Sampel}

Sampel adalah bagian atau jumlah dan karakteritik yang dimiliki oleh populasi tersebut. Bila populasi besar, dan peneliti tidak mungkin mempelajari semua yang ada pada populasi, misal karena keterbatan dana, tenaga dan waktu, maka peneliti akan mengambil sampel dari populasi itu. Apa yang dipelajari dari sampel itu, kesimpulannya akan diberlakukan untuk populasi. Untuk itu sampel yang diambil dari populasi harus betul-betul representative (Sugiyono, 2016). 
Menurut (Arikunto, 2019) apabila populasi kurang dari 100 maka sebaiknya diambil semua sebagai sampel sehingga teknik pengambilan sampel menggunakan metode sensus. Karena populasi responden sejumlah 87, peneliti mengambil semua untuk dijadikan sampel (Ruhamak \& Rahmadi, 2019).

\section{Instrumen Penelitian}

Instrumen adalah alat yang digunakan untuk mengumpulkan data yang diperlukan sehubungan dengan permasalahan penelitian. Melalui instrumen dapat diperoleh data dan jawaban terhadap permasalahan yang diajukan untuk diolah dalam kegiatan penelitian.

Instrumen yang digunakan dalam penelitian ini adalah Kuesioner. Alasan peneliti menggunakan kuesioner karena merupakan alat yang efektif untuk memperoleh data untuk penelitian dan banyak digunakan dalam penelitian sejenis.

Dari definisi operasional variabel, terdapat indikator varibel. Peneliti mengambil masing-masing indikator per variabel untuk ditarik kemudian dibuat suatu pertanyaan/pernyataan dan dibagikan kepada responden untuk memperoleh data

Bentuk penilaian dari masing-masing item pertanyaan dibuat tabel dimana masing -masing kolom terdapat kriteria skor menggunakan skala likert yakni 1-5.

Skala Likert adalah skala yang digunakan untuk mengukur persepsi, sikap atau pendapat seseorang atau kelompok mengenai sebuah peristiwa atau

fenomena sosial, berdasarkan definisi operasional yang telah ditetapkan oleh peneliti. Penjabaran skala likert dalam kuesioner penelitian untuk jawaban Sangat tidak setuju bernilai 1, tidak setuju bernilai 2, cukup setuju bernilai 3, setuju bernilai 4 dan sangat setuju bernilai 5 .

\section{Teknik Pengumpulan Data}

\section{Sumber dan Langkah-langkah Pengumpulan Data}

\section{Sumber Data}

Data Primer, yaitu data yang diperoleh dari tanggapan responden terhadap item pertanyaan yang diajukan dalam kuesioner, atau dengan kata lain data yang diperoleh langsung dari lokasi penelitian dimana penulis mengadakan pengumpulan data melalui 
kuesioner, artinya penulis menyusun pertanyaan dalam bentuk kalimat dengan opsi jawaban yang tersedia dalam form yang telah disediakan.

Data Sekunder, yaitu data yang diperoleh dari dokumen-dokumen dan arsip perusahaan yang ada kaitannya dengan penelitian ini, atau data yang diperoleh dari berbagai literature dan sumber-sumber lain yang berhubungan dengan masalah yang sedang diteliti.

\section{Langkah-langkah Pengumpulan Data}

Dalam pengumpulan data, peneliti menggunakan beberapa metode antara lain :

a. Observasi

Observasi adalah kegiatan teknik pengumpulan data dengan cara melakukan pengamatan langsung di lapangan atas segala yang diteliti.

b. Wawancara

Wawancara adalah kegiatan melakukan tanya jawab langsung melalui tatap muka kepada narasumber yakni pimpinan perusahaan/instansi, responden maupun karyawan yang ada dalam perusahaan tersebut untuk memperoleh data pendukung dalam kegiatan penelitian.

c. Studi Kepustakaan

Pengumpulan data yang diperoleh dari kepustakaan seperti membaca buku ilmiah, majalah maupun media yang berhubungan dengan masalah dengan pembahasan penelitian.

d. Kuesioner

Kuesioner adalah sejumlah pertanyaan secara tertulis yang akan dijawab oleh responden agar peneliti memperoleh data lapangan untuk memecahkan permasalahan yang ada dalam penelitian serta menguji hipotesis yang telah ditetapkan. 
Dalam penelitian ini, kuesioner yang digunakan adalah kuesioner tertutup, yaitu model pertanyaan dimana pertanyaan tersebut telah tersedia jawaban, sehingga responden hanya memilih dari alternatif jawaban yang sesuai dengan pendapat atau pilihannya.

Pertanyaan tertutup tersebut menerangkan tanggapan responden terhadap variabel lingkungan kerja, kompetensi, insentif dan kinerja karyawan. Untuk nilai atau skor dari tiap jawaban yang diberikan oleh responden menggunakan skala likert. Peneliti menentukan kriteria skor sebagai berikut:

1. Untuk jawaban Sangat Setuju responden diberi skor 5

2. Untuk jawaban Setuju responden diberi skor 4

3. Untuk jawaban Cukup Setuju responden diberi skor 3

4. Untuk jawaban Tidak Setuju diberi skor 2

5. Untuk jawaban Sangat Tidak Setuju diberi skor 1

\section{Teknik Analisis Data}

\section{Analisa Model Struktural}

Menurut (Hussein, 2015) Analisa pada PLS dilakukan dengan tiga tahap:
a. Analisa outer model
b. Analisa inner model
c. Pengujian Hipotesa.

Analisa outer model dilakukan untuk memastikan bahwa measurement yang digunakan layak untuk dijadikan pengukuran (valid dan reliabel). Analisa outer model dapat dilihat dari beberapa indikator:
a. Convergent validity
b. Discriminant validity
c. Unidimensionality

Sedangkan analisa inner model/analisa struktural model dilakukan untuk memastikan bahwa model struktural yang dibangun robust dan akurat. Evaluasi inner model dapat dilihat dari beberapa indikator yang meliputi: 
a. Koefisien determinasi (R2)

b. Predictive Relevance (Q2)

c. Goodness of Fit Index (GoF)

Untuk pengujian Hipotesa dilakukan dengan melihat nilai probabilitasnya dan t- statistik nya. Untuk nilai probabilitas, nilai p-value dengan alpha 5\% adalah kurang dari 0,05. Nilai t-tabel untuk alpha 5\% adalah 1,96. Sehingga kriteria penerimaan Hipotesa adalah ketika t-statistik > t-tabel.

Analisa Outer Model

Analisa Outer Model ini menspesifikasi hubungan antar variabel laten dengan indikator-indikatornya. atau dapat dikatakan bahwa outer model mendefinisikan bagaimana setiap indikator berhubungan dengan variabel latennya. Uji yang dilakukan pada outer model :

a. Convergent Validity. Nilai convergen validity adalah nilai loading faktor pada variabel laten dengan indikator-indikatornya. Nilai yang diharapkan $>0.7$.

b. Discriminant Validity. Nilai ini merupakan nilai cross loading faktor yang berguna untuk mengetahui apakah konstruk memiliki diskriminan yang memadai yaitu dengan cara membandingkan nilai loading pada konstruk yang dituju harus lebih besar dibandingkan dengan nilai loading dengan konstruk yang lain.

c. Composite Reliability. Data yang memiliki composite reliability $>0.7$ mempunyi reliabilitas yang tinggi.

d. Average Variance Extracted (AVE). Nilai AVE yang diharapkan >0.5.

e. Cronbach Alpha. Uji reliabilitas diperkuat dengan Cronbach Alpha. Nilai diharapkan $>0.6$ untuk semua konstruk.

\section{Pengujian Hipotesa}

Secara umum metode explanatory research adalah pendekatan metode yang menggunakan PLS. Hal ini disebabkan pada metode ini terdapat pengujian Hipotesa. Menguji hipotesis dapat dilihat dari nilai t-statistik dan nilai probabilitas. Untuk pengujian 


\section{JURNAL EKBIS ANALISIS, PREDIKSI, DAN INFORMASI}

hipotesis menggunakan nilai statistik maka untuk alpha 5\% nilai t-statistik yang digunakan adalah 1,96. Sehingga kriteria penerimaan/penolakan Hipotesa adalah Ha diterima dan $\mathrm{H} 0$ di tolak ketika t-statistik > 1,96. Untuk menolak/menerima Hipotesis menggunakan probabilitas maka Ha di terima jika nilai $\mathrm{p}<0,05$.

\section{HASIL DAN PEMBAHASAN}

\section{Uji Validitas}

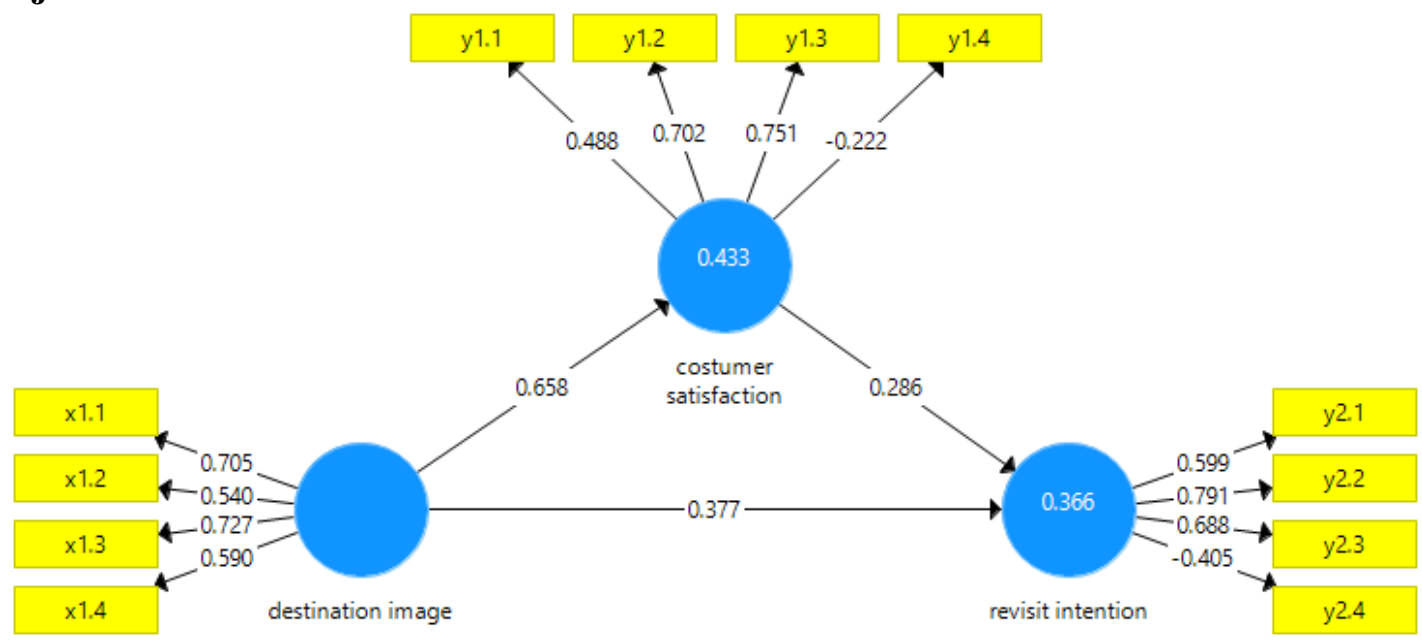

Tabel 1. Hasil uji validitas

\begin{tabular}{|l|r|r|r|r|r|}
\hline & \multicolumn{1}{|l|}{$\begin{array}{l}\text { Original } \\
\text { Sample (O) }\end{array}$} & $\begin{array}{l}\text { Sample } \\
\text { Mean (M) }\end{array}$ & $\begin{array}{l}\text { Standard } \\
\text { Deviation } \\
\text { (STDEV) }\end{array}$ & $\begin{array}{l}\text { T Statistics } \\
(\mid \mathbf{O} / \text { STDEV|) }\end{array}$ & P Values \\
\hline x1.1 <- destination image & 0,705 & 0,685 & 0,090 & 7,804 & $\mathbf{0 , 0 0 0}$ \\
\hline x1.2 <- destination image & 0,540 & 0,527 & 0,149 & 3,621 & $\mathbf{0 , 0 0 0}$ \\
\hline x1.3 <- destination image & 0,727 & 0,732 & 0,076 & 9,543 & $\mathbf{0 , 0 0 0}$ \\
\hline x1.4 <- destination image & 0,590 & 0,570 & 0,141 & 4,191 & $\mathbf{0 , 0 0 0}$ \\
\hline $\begin{array}{l}\text { y1.1 <- Customer } \\
\text { satisfaction }\end{array}$ & 0,488 & 0,424 & 0,243 & 2,005 & $\mathbf{0 , 0 4 6}$ \\
\hline $\begin{array}{l}\text { y1.2 <- Customer } \\
\text { satisfaction }\end{array}$ & 0,702 & 0,695 & 0,128 & 5,470 & $\mathbf{0 , 0 0 0}$ \\
\hline $\begin{array}{l}\text { y1.3 <- Customer } \\
\text { satisfaction }\end{array}$ & 0,751 & 0,732 & 0,115 & 6,536 & $\mathbf{0 , 0 0 0}$ \\
\hline
\end{tabular}




\begin{tabular}{|l|r|r|r|r|r|} 
y1.4 <- Customer & $-0,222$ & $-0,206$ & 0,196 & 1,131 & $\mathbf{0 , 2 5 9}$ \\
\hline satisfaction & 0,599 & 0,570 & 0,137 & 4,366 & $\mathbf{0 , 0 0 0}$ \\
\hline y2.1 <- revisit intention & 0,791 & 0,791 & 0,064 & 12,328 & $\mathbf{0 , 0 0 0}$ \\
\hline y2.2 <- revisit intention & 0,688 & 0,679 & 0,110 & 6,256 & $\mathbf{0 , 0 0 0}$ \\
\hline y2.3 <- revisit intention & $-0,405$ & $-0,404$ & 0,156 & 2,593 & $\mathbf{0 , 0 1 0}$ \\
\hline y2.4 <- revisit intention &
\end{tabular}

Sumber : data primer yang diolah peneliti, (2020)

Dari tabel diatas dapat diketahui bahwa seluruh indikator dari variabel destination image (X1), Customer Satisfaction (Y1) dan Revisit Intention (Y2) yang memiliki nilai korelasi (original sample) diatas 0,7 yaitu x1.1, x1.3, y1.2, y1.3 dan y2.2 mampu untuk mengungkapkan sesuatu yang akan diukur oleh kuesioner tersebut, sedangkan indikator $\mathrm{x} 1.2, \mathrm{x} 1.4, \mathrm{y} 1.1, \mathrm{y} 1.4, \mathrm{y} 2.1, \mathrm{y} 2.3$ dan y2.4 yang hanya memiliki korelasi dibawah 0,7 (tidak valid) sehingga agar diperoleh model fit maka indikator yang tidak valid harus didrop (dihapus) dari model.

\section{Uji Reliabilitas}

Tabel 2 Construct Reliability and Validity

\begin{tabular}{|l|r|r|r|}
\hline & $\begin{array}{l}\text { Composite } \\
\text { Reliability }\end{array}$ & $\begin{array}{l}\text { Average Variance } \\
\text { Extracted (AVE) }\end{array}$ & Keterangan \\
\hline Customer satisfaction & $\mathbf{0 , 8 0 5}$ & $\mathbf{0 , 5 1 1}$ & Reliabel \\
\hline destination image & $\mathbf{0 , 8 1 3}$ & $\mathbf{0 , 5 2 4}$ & Reliabel \\
\hline revisit intention & $\mathbf{0 , 8 4 2}$ & $\mathbf{0 , 5 7 5}$ & Reliabel \\
\hline
\end{tabular}

Sumber : data primer yang diolah peneliti, (2020)

Dari tabel diatas diperoleh hasil bahwa nilai dari composite reliability dari masingmasing variabel destination image (X1) 0,805 Customer satisfaction (Y1) 0,813 dan revisit intention (Y2) 0,842 yang mana keseluruhan nilai tersebut lebih besar dari nilai cut off value 0,7, adapun nilai AVE dari masing-masing variabel diatas 0,5 maka tidak terdapat permasalahan reliabilitas / unindimensionality.

\section{Analisa inner model}

Tabel 3 r square

\begin{tabular}{|l|r|}
\hline Konstruk & R Square \\
\hline Customer satisfaction & $\mathbf{0 , 4 3 3}$ \\
\hline
\end{tabular}




\section{JURNA A EKBIS ANALISIS, PREDIKSI, DAN INFORMASI}

\section{\begin{tabular}{|r|r|}
\hline revisit intention & $\mathbf{0 , 3 6 6}$ \\
\hline
\end{tabular} \\ Sumber : data primer yang diolah peneliti (2020)}

Predictive relevance $\left(\mathrm{Q}^{2}\right)$

$\mathrm{Q}^{2}=1-\left(1-\mathrm{R} 1^{2}\right)\left(1-\mathrm{R} 2^{2}\right) \ldots \ldots\left(1-\mathrm{Rp}^{2}\right) \ldots$

$\mathrm{Q}^{2}=1-(1-0,433)(1-0,366)$

$Q^{2}=0,641$

Berikutnya pengujian goodness of fit $(\mathrm{GoF})$

$\mathrm{GoF}=\sqrt{\mathrm{AVE} \times \mathrm{R}^{2}}$

$\mathrm{GoF}=0,458$

Dari hasil diatas dapat diketahui bahwa nilai GoF tergolong besar karena lebih dari 0,38 . Sehingga dari pengujian R2, Q2 dan GoF terlihat bahwa model yang dibentuk adalah robust. Sehingga pengujian hipotesa dapat dilakukan.

\section{Uji Hipotesis}

\begin{tabular}{|c|c|c|c|c|c|}
\hline Hipotesis & $\begin{array}{c}\text { Original } \\
\text { Sample } \\
(\mathbf{O})\end{array}$ & $\begin{array}{c}\text { T Statistics } \\
(\mid \text { O/STDEV|) }\end{array}$ & $\begin{array}{c}\mathbf{P} \\
\text { Values }\end{array}$ & Kesimpulan \\
\hline $\mathbf{H 1}$ & $\begin{array}{c}\text { destination image -> } \\
\text { Customer satisfaction }\end{array}$ & 0,658 & 10,271 & $\mathbf{0 , 0 0 0}$ & Diterima \\
\hline $\mathbf{H 2}$ & $\begin{array}{c}\text { destination image }-> \\
\text { revisit intention }\end{array}$ & 0,377 & 3,357 & $\mathbf{0 , 0 0 1}$ & Diterima \\
\hline $\mathbf{H 3}$ & $\begin{array}{c}\text { Customer satisfaction } \\
\text {-> revisit intention }\end{array}$ & 0,286 & 2,535 & $\mathbf{0 , 0 1 2}$ & Diterima \\
\hline $\mathbf{H 4}$ & $\begin{array}{c}\text { destination image }> \\
\text { Customer satisfaction } \\
\text {-> revisit intention }\end{array}$ & 0,565 & 8,312 & $\mathbf{0 , 0 0 0}$ & Diterima \\
\hline
\end{tabular}

Sumber : data primer yang diolah peneliti (2020)

Tabel di atas menunjukkan bahwa pengaruh variabel DI terhadap CS positif $(0,658)$ dan signifikan pada $\alpha=0,05$ dengan nilai statistik 10,271 > 1,96. Pengaruh variabel DI terhadap RI positif $(0,377)$ dan signifikan pada $\alpha=0,05$ dengan nilai statistik $3,357>$ 1,96. Pengaruh variabel CS terhadap RI positif $(0,286)$ dan signifikan pada $\alpha=0,05$ dengan nilai statistik 2,535 > 1,96. Pengaruh variabel DI terhadap RI melalui CS positif $(0,565)$ dan signifikan pada $\alpha=0,05$ dengan nilai statistik 8,312>1,96.

\section{Pengujian Hipotesis H1}

Hipotesis H1 menyatakan bahwa Destination image (DI) berpengaruh terhadap Customer satisfaction (CS). Hasil uji terhadap koefisien parameter antara DI terhadap CS 
menunjukkan adanya pengaruh yang positif sebesar 0,658 (berdasarkan nilai Original Sample Estimate DI -> CS pada nilai 0,658) dengan nilai T statistik sebesar 10,271 dan signifikan pada $\alpha=0,05$. Nilai $\mathrm{T}$ statistik tersebut jauh di atas nilai kritis 1,96 , dengan demikian hipotesis pertama dapat diterima.

Hasil ini mendukung penelitian sebelumnya yang dilakukan oleh (Chiu et al., 2016; Hanif \& Kusumawati, 2016; Lee, 2018; Nisco, 2015; Pantouw \& Pangemanan, 2014; Samsudin \& Worang, 2016; Wibowo, 2016) yang mana semakin baik citra destinasi maka semakin puas perasaan yang dirasa oleh konsumen dimana hal tersebut akan memberikan suatu pengalaman yang baik dimasa yang akan datang.

\section{Pengujian Hipotesis $\mathrm{H} 2$}

Hipotesis H2 menyatakan bahwa Destination image (DI) berpengaruh terhadap Revisit intention (RI). Hasil uji terhadap koefisien parameter antara DI terhadap RI menunjukkan adanya pengaruh positif sebesar 0,377 (berdasarkan nilai Original Sample Estimate DI -> RI pada nilai 0,377) dengan nilai T statistik sebesar 3,357 dan signifikan pada $\alpha=0,05$. Nilai T nya jauh di atas nilai kritis 1,96 , dengan demikian hipotesis kedua diterima.

Hasil ini mendukung penelitian sebelumnya yang dilakukan oleh (Raheem et al., 2014; Timur, 2019; Trung \& Khalifa, 2019; Wibowo, 2016) dimana semakin baik suatu citra destinasi akan berdampak pada keinginan konsumen untuk datang atau berkunjung kembali ke tempat tersebut.

\section{Pengujian Hipotesis H3}

Hipotesis H3 menyatakan bahwa Customer satisfaction (CS) berpengaruh terhadap Revisit Intention (RI). Hasil uji terhadap koefisien parameter antara CS terhadap RI menunjukkan adanya pengaruh positif sebesar 0,286 (berdasarkan nilai Original Sample Estimate CS -> RI pada nilai 0,286) dengan nilai T statistik sebesar 2,535 dan signifikan pada $\alpha=0,05$. Nilai T nya jauh di atas nilai kritis 1,96 , dengan demikian hipotesis ketiga diterima.

Hasil ini mendukung penelitian sebelumnya yang dilakukan oleh (Chiu et al., 2016; 
Raheem et al., 2014; Rajesh, 2013; Samsudin \& Worang, 2016; Wibowo, 2016; Wong \& Lui, 2018) yang manan ketika konsumen semakin puas maka keinginan untuk datang berkunjung kembali ke tempat tersebut juga akan semakin besar.

\section{Pengujian Hipotesis H4}

Hipotesis H4 menyatakan bahwa Destination image (DI) berpengaruh terhadap Revisit intention (RI) Melalui Customer satisfaction (CS). Hasil uji terhadap koefisien parameter antara DI terhadap RI melalui CS menunjukkan adanya pengaruh positif sebesar 0,565 (berdasarkan nilai Original Sample Estimate DI -> CS -> RI pada nilai $0,565)$ dengan nilai $T$ statistik sebesar 8,312 dan signifikan pada $\alpha=0,05$. Nilai T nya jauh di atas nilai kritis 1,96, dengan demikian hipotesis keempat diterima.

Hasil analisis jalur menunjukkan bahwa Brand Image (X1) secara langsung mempengaruhi Revisit Intention sebesar 37,7\% dan mempengaruhi secara tidak langsung, yaitu dimediasi oleh Customer Satisfaction sebesar 18,8\% dan total pengaruh Destination Image terhadap Revisit Intention menjadi 56,5\%. Oleh karena adanya kenaikan pengaruh dari yang semula 37,7\% menjadi 56,5\% maka Brand Image dapat dikatakan memediasi secara sempurna (Ruhamak \& Rahayu, 2016).

\section{KESIMPULAN DAN SARAN}

Citra destinasi berpengaruh signifikan terhadap kepuasan konsumen yang mana kepuasan tersebut semakin mendorong konsumen untuk datang berkunjung kembali, semakin baik dan semakin banyak destinasi yang ditawarkan tidak hanya dalam pembelajaran tetapi juga sebagai sarana melepas penat setelah beraktivitas dimana hal tersebut mampu membuat konsumen merasa puas sehingga apa yang mereka rasakan pada saat berkunjung ditempat tersebut akan menciptakan suatu perasaan atau pengalaman pada diri mereka yang mampu membuat suatu pemikiran atau mindset bagi diri mereka bahwa mereka harus datang kembali ke tempat tersebut yang tidak hanya untuk meningkatkan kemampuan berbahasa inggris ke tingkat yang lebih tinggi lagi, namun juga mendatangi kembali tempat - tempat wisata yang ada di sekitar yang terus dikembangkan karena memiliki potensi untuk menggaet wisatawan dari luar daerah.

Maka dari itu perlu adanya pemanfaatan di bidang pemasaran dengan menggunakan media sosial / e-marketing yang dikemas dalam konten foto maupun video agar 
jangkauan pengenalan ke konsumen menjadi semakin luas dan mampu menarik wisatawan yang pernah berkunjung untuk dapat datang kembali.

\section{UCAPAN TERIMA KASIH}

Terima kasih kepada Kementrian Riset dan Teknologi / Badan Riset dan Inovasi Nasional serta seluruh pihak yang telah membantu sehingga penelitian ini dapat terselesaikan.

\section{DAFTAR PUSTAKA}

al-jum'ah, ais nurbiyah. (2018). Kalend Osen, Kampung Inggris, dan Kemudrtadan Berbahasa | Locita. https://locita.co/tokoh/siapa/kalend-osen-kampung-inggrisdan-kemurtadan-berbahasa

Arikunto, S. (2019). Prosedur penelitian. Rineka cipta.

Chiu, W., Zeng, S., \& Cheng, P. S.-T. (2016). The influence of destination image and tourist satisfaction on tourist loyalty: a case study of Chinese tourists in Korea. International Journal of Culture, Tourism and Hospitality Research.

Hanif, A., \& Kusumawati, A. (2016). PENGARUH CITRA DESTINASI TERHADAP KEPUASAN WISATAWAN SERTA DAMPAKNYA TERHADAP LOYALITAS WISATAWAN (Studi pada Wisatawan Nusantara yang Berkunjung ke Kota Batu). Jurnal Administrasi Bisnis S1 Universitas Brawijaya, 38(1), 44-52.

Hussein, A. S. (2015). Penelitian Bisnis dan Manajemen Menggunakan Partial Least Squares dengan SmartPLS 3.0. Universitas Brawijaya, 1, 1-19. https://doi.org/10.1023/A:1023202519395

Lee, H. C. (2018). THE STUDY OF DESTINATION IMAGE, SERVICE QUALITY, SATISFACTION AND BEHAVIORAL INTENTION - AN EXAMPLE OF DAPENG BAY NATIONAL SCENIC AREA. 11(3), 25-36.

Nisco, A. De. (2015). Tourism satisfaction effect on general country image, destination image, and. April. https://doi.org/10.1177/1356766715577502 
Pantouw, P., \& Pangemanan, S. S. (2014). THE EFFECT OF DESTINATION IMAGE AND TOURIST SATISFACTION ON INTENTION TO REVISIT IN LEMBEH HILL RESORT. EMBA, 2(3), 49-57. https://doi.org/10.1080/14768320500230185

Raheem, A., Mohammed, J., Salehuddin, M., Zahari, M., Talib, S. A., \& Suhaimi, M. Z. (2014). The Causal Relationships between Destination Image , Tourist Satisfaction and Revisit Intention : A Case of the United Arab Emirates. International Journal of Economics and Management Engineering, 8(10), 3346-3352.

Rajesh, R. (2013). Impact of Tourist Perceptions, Destination Image and Tourist Satisfaction on Destination Loyalty: A Conceptual Model. PASOS. Revista de Turismo y Patrimonio Cultural, 11(3), 67-78.

https://doi.org/10.25145/j.pasos.2013.11.039

Ruhamak, M. D., \& Rahayu, B. (2016). Pengaruh Word Of Mouth Terhadap Purchase Intention Melalui Brand Image Pada Lembaga Kursus Bahasa Inggris Dynamic English Course Pare. Jurnal Ekonomi Universitas Kadiri, 1(2), 188-204.

Ruhamak, M. D., \& Rahmadi, A. N. (2019). Pengaruh E-WOM, Brand Image dan Brand Trust Terhadap Keputusan Konsumen (Studi Kasus Pada Lembaga Kursus Fajar English Course Pare-Kediri). BISNIS: Jurnal Bisnis Dan Manajemen Islam, $7(2), 233-246$.

Samsudin, A., \& Worang, F. G. (2016). ANALYSING THE EFFECTS OF DESTINATION IMAGE AND TOURIST SATISFACTION ON REVISIT INTENTION IN CASE BUNAKEN NATIONAL PARK. 16(04), 23-34.

Stylos, N., Vassiliadis, C. A., Bellou, V., \& Andronikidis, A. (2016). Destination images, holistic images and personal normative beliefs: Predictors of intention to revisit a destination. In Tourism Management (Vol. 53). https://doi.org/10.1016/j.tourman.2015.09.006

Sugiyono. (2016). Metode Penelitian dan Pengembangan (Research and Development/R\&D). In Bandung: Alfabeta. https://doi.org/10.1016/j.drudis.2010.11.005

Timur, B. (2019). Service Quality , Destination Image and Revisit Intention 
Relationships at Thermal Tourism Businesses. Journal of Gastronomy, Hospitality, and Travel, 1(1), 38-48. https://doi.org/10.33083/0.2018.3

Trung, N. V. H., \& Khalifa, G. S. A. (2019). Impact of Destination Image Factors on Revisit Intentions of Hotel's International Tourists in Ba Ria-Vung Tau (BR-VT) The Mediating Role of Positive Word-of-Mouth. International Journal on Recent Trends in Business and Tourism, 3(2), 98-107.

Whang, H., Yong, S., \& Ko, E. (2016). Pop culture, destination images, and visit intentions: Theory and research on travel motivations of Chinese and Russian tourists. Journal of Business Research, 69(2), 631-641.

https://doi.org/10.1016/j.jbusres.2015.06.020

Wibowo, S. F. (2016). THE INFLUENCE OF DESTINATION IMAGE AND TOURIST SATISFACTION TOWARD REVISIT INTENTION OF SETU BABAKAN BETAWI CULTURAL VILLAGE. Jurnal Riset Manajemen Sains Indonesia (JRMSI), 7(1), 136-156.

Wong, N., \& Lui, E. (2018). SATISFACTION DRIVERS AND REVISIT INTENTION OF INTERNATIONAL SATISFACTION DRIVERS AND REVISIT INTENTION OF. July, 0-13. 